\title{
ACTUALITĂȚI ÎN DIAGNOSTICUL ŞI TERAPIA HEPATOBLASTOMULUI PEDIATRIC CU METASTAZE PULMONARE
}

\author{
Oana Tatiana Miron' ${ }^{1}$, Anca Maria Adavidoaiei², Vlad-Adrian Afrăsânie ${ }^{3}$, \\ Doina Mihăilă ${ }^{4}$, Ingrith Miron ${ }^{1,5}$ \\ ${ }^{1}$ Universitatea de Medicină şi Farmacie „, Gr. T. Popa “, Iaşi \\ ${ }^{2}$ Clinica a II-a Boli Infecțioase, Spitalul Clinic de Boli Infecțioase ,Sf. Parascheva“, Iaşi \\ ${ }^{3}$ Secția Oncologie Medicală, Institutul Regional de Oncologie, Iaşi \\ ${ }^{4}$ Laboratorul de Anatomie Patologică, \\ Spitalul Clinic de Urgență pentru Copii ,,Sf. Maria“", Iaşi \\ ${ }^{5}$ Clinica de Hemato-Oncologie, Spitalul Clinic de Urgență pentru Copii ,,Sf. Maria“, Iaşi
}

\begin{abstract}
REZUMAT
Deşi frecvența hepatoblastomului este redusă, acesta reprezintă cea mai comună tumoră hepatică primară malignă a copilului. Prognosticul bolii s-a îmbunătățit considerabil în ultimele decenii, datorită progreselor terapeutice oncologice şi chirurgicale. Totuşi, tumorile aflate într-un stadiu avansat la momentul diagnosticului au în continuare un prognostic rezervat. Prezentăm cazul unui copil de 2 ani şi 9 luni, diagnosticat în februarie 2014 cu hepatoblastom, cu risc înalt (metastaze pulmonare), pentru care s-a intervenit chirurgical practicându-se excizia completă a tumorii. Ulterior, s-a inițiat chimioterapie conform protocolului SIOPEL-4 modificat: astfel, blocurile de chimioterapie care ar fi trebuit administrate preoperator au fost utilizate postoperator. După finalizarea chimioterapiei, examenul CT toraco-abdominal efectuat în septembrie 2014 a indicat răspuns complet al bolii la tratament. Evaluarea periodică a pacientului a relevat până în prezent absența semnelor de recidivă locală tumorală, absența metastazelor şi un status de performanță de 80 pe scala Lansky. Utilizarea terapiilor moleculare țintite, a transplantului hepatic şi a unor noi chimioterapice poate reprezenta în viitor o modalitate de îmbunătățire a prognosticului pacienților cu hepatoblastom cu risc înalt. De asemenea, modificarea protocoalelor de chimioterapie ar putea reprezenta o opțiune pentru îndeplinirea acestui scop.
\end{abstract}

Cuvinte cheie: metastaze pulmonare, protocol SIOPEL-4, răspuns tumoral complet

\section{INTRODUCERE}

Hepatoblastomul reprezintă cea mai frecventă tumoră hepatică malignă primară a copilului, deşi are o incidență anuală redusă, de doar 1,5 cazuri la 1 milion de copii sub vârsta de 15 ani. (1) Prognosticul bolii s-a îmbunătățit semnificativ în ultimele patru decenii datorită progreselor chimioterapiei şi ale tehnicilor chirurgicale care pot asigura rezecția completă a tumorii. (2) Grupul de Studiu al Tumorilor Hepatice Epiteliale din cadrul Societății de Oncologie Pediatrică Internațională (SIOPEL) re- comandă utilizarea rezecției tumorale însoțită de chimioterapie preoperatorie şi/sau postoperatorie, în funcție de stadiul tumorii la momentul diagnosticului.

În ciuda dezvoltării metodelor terapeutice, în prezent se încearcă găsirea unor noi modalităţi de tratament care să aducă beneficii pacienților cu hepatoblastom în stadiu avansat. Printre acestea se numără utilizarea unor noi agenți chimioterapici (irinotecan, oxaliplatin), a terapiilor moleculare țintite sau ale unor protocoale noi de chimioterapie. (1) 


\section{PREZENTARE DE CAZ}

Prezentăm cazul unui copil de sex masculin, în vârstă de 2 ani şi 9 luni, internat în secția de Hemato-Oncologie a Spitalului Clinic de Urgență pentru Copii „Sf. Maria“ în ianuarie 2014 pentru investigarea unei formațiuni tumorale epigastrice.

Anamneza şi examenul clinic au relevat: dureri abdominale, grețuri, vărsături; la palparea abdomenului s-a decelat o formațiune tumorală epigastrică bine delimitată, de consistență crescută, nedureroasă, cu diametru de $\sim 10 \mathrm{~cm}$ şi tegumente supraiacente normale; ficat ce coboară la $\sim 5 \mathrm{~cm}$ sub rebordul costal; tuse, polipnee şi murmur vezicular înăsprit bilateral. Restul organelor şi sistemelor, în limite normale.

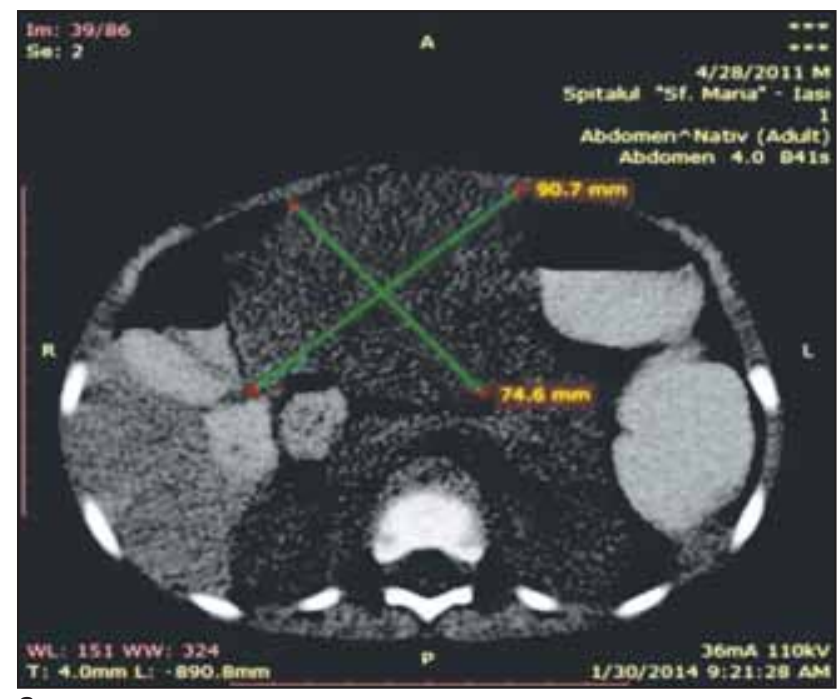

a

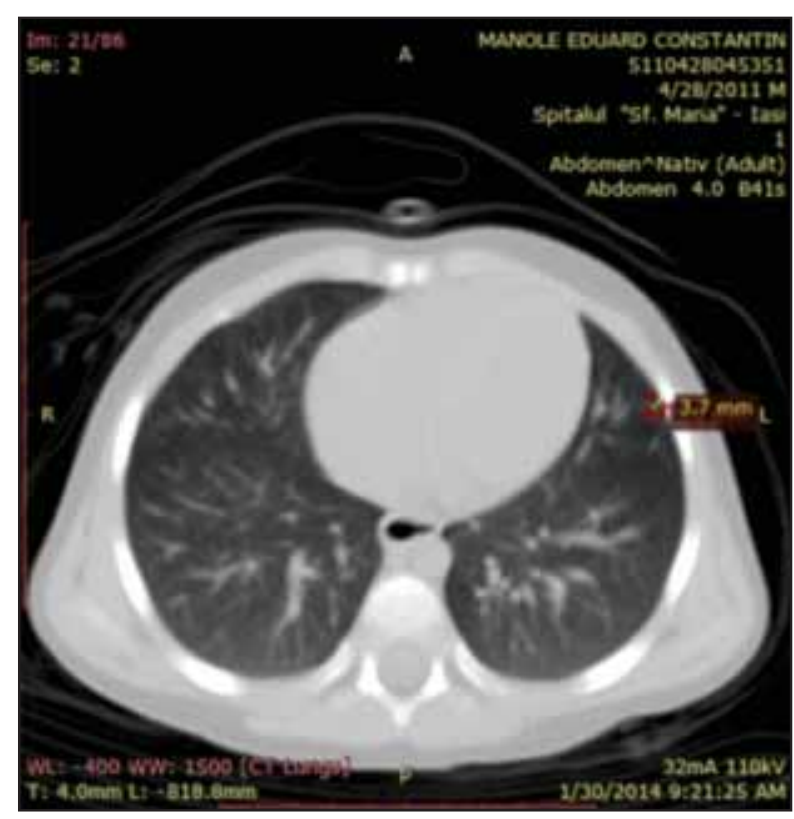

C
Investigațiile biologice au atestat: sindrom inflamator (fibrinogen $=522 \mathrm{mg} / \mathrm{dl}$ ), sindrom de hepatocitoliză $(\mathrm{TGO}=155 \mathrm{UI} / 1)$, trombocitoză (trombocite $\left.=442.000 / \mathrm{mm}^{3}\right)$ şi alfa-fetoproteina $($ AFP $)>$ $30.000 \mathrm{UI} / 1$.

Investigațiile imagistice au decelat prin ecografie abdominală o formațiune tumorală neomogenă, bine delimitată periferic, cu diametrul de $\sim 7 / 8 \mathrm{~cm}$, situată retroperitoneal, cu dezvoltare predominant pe stânga. Examenul CT toraco-abdomino-pelvin descrie o formațiune tumorală expansivă cu dimensiuni de 7/9/9 cm, neomogenă, multiple zone de necroză intratumorală, localizată pe topografia lobului hepatic stâng (Fig. $1-$ a, b) şi noduli radioopaci infracentimetrici, localizați subpleural la nivelul
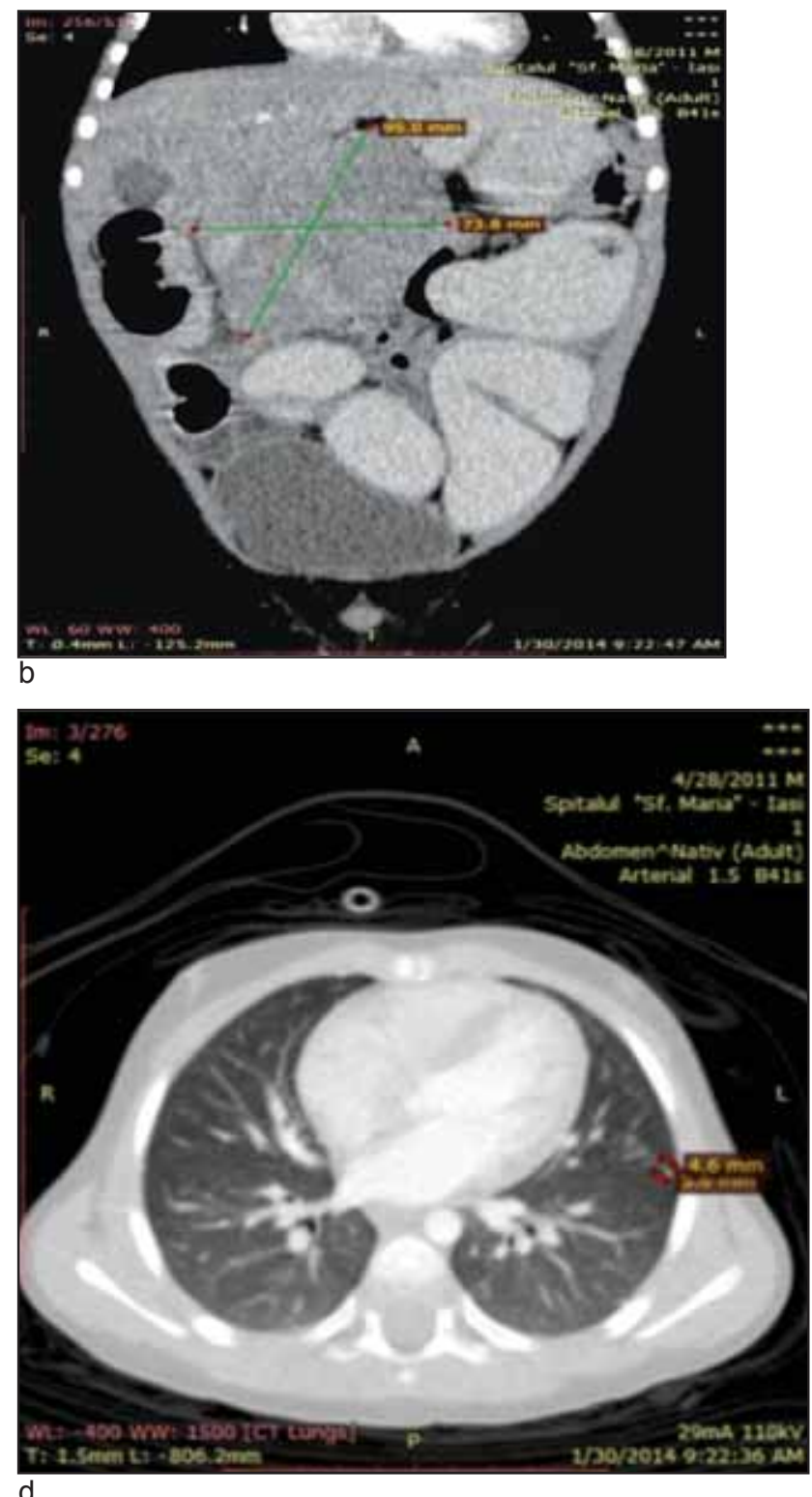

FIGURA 1 - a. Formațiune tumorală lob hepatic stâng - secțiune sagitală; b. Formațiune tumorală lob hepatic stâng secțiune cranio-caudală; $c$, d. Leziuni secundare pulmonare infracentimetrice 
hemitoracelui stâng, cu aspect caracteristic de leziuni secundare (Fig. $1-\mathrm{c}, \mathrm{d}$ ).

S-au explicat aparținătorilor posibilitățile terapeutice, riscurile și beneficiile protocolului SIOPEL-4 şi s-a propus iniţierea chimioterapiei preoperatorii. Aceştia au refuzat terapia antineoplazică şi au decis ca pacientul să fie operat. În februarie 2014, s-a intervenit chirurgical, efectuându-se excizia completă a tumorii în limite de siguranță oncologică.

Examenul anatomo-patologic a confirmat diagnosticul de hepatoblastom epitelial mixt cu elemente hepatocitare embrionare şi fetale. (Fig. $2-a, b, c, d$ )

Pe baza investigațiilor efectuate se stabileşte diagnosticul final de hepatoblastom epitelial mixt risc înalt (cu metastaze pulmonare).

Ulterior, aparținătorii s-au răzgândit şi au fost de acord să se administreze chimioterapie conform protocolului SIOPEL-4 modificat.

La finalizarea blocurilor A1, A2 şi A3 de chimioterapie pacientul a fost investigat prin examen CT toraco-abdominal care a atestat răspuns parțial

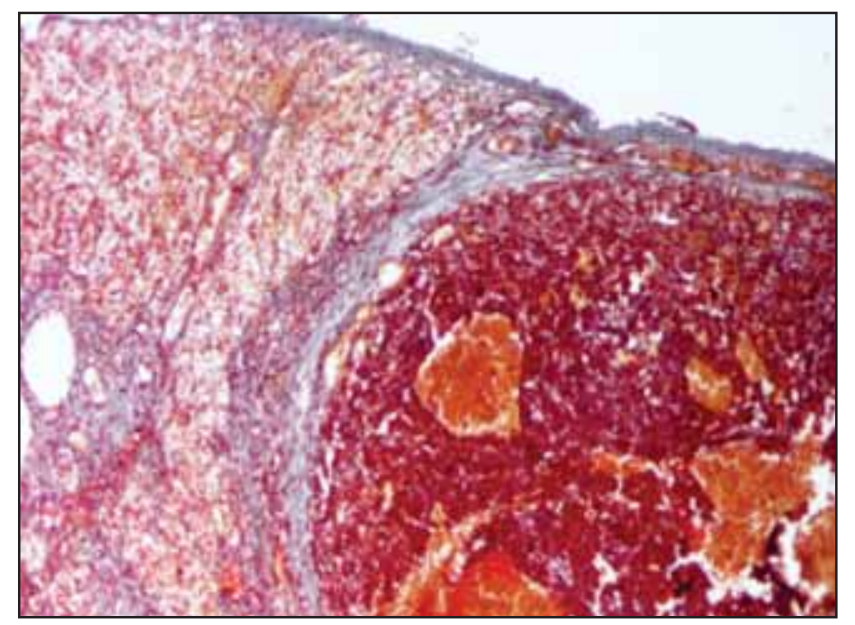

a

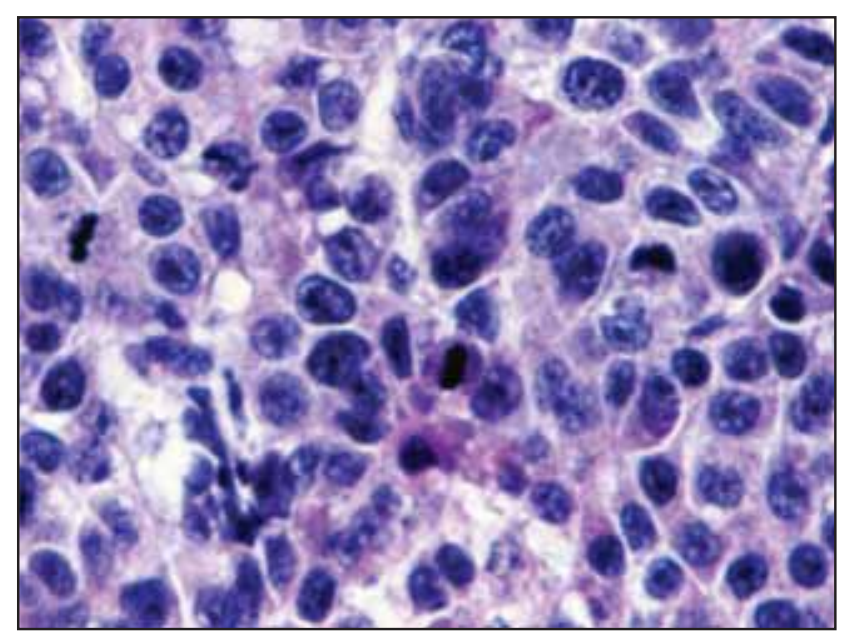

c al metastazelor pulmonare la tratament, argumentându-se astfel continuarea cu blocul $\mathrm{C}$ de chimioterapie.

După a 9-a cură de chimioterapie, în iulie 2014, la scurt timp de la externare, copilul a prezentat un episod de neutropenie febrilă, care a evoluat favorabil sub tratament cu antibiotic, antimicotice, factor de creştere granulocitar şi transfuzii sanguine. După a 11-a cură de chimioterapie, în septembrie 2014, la încheierea protocolului SIOPEL-4 modificat, pacientul a fost reexaminat prin examen CT toraco-abdomino-pelvin care a evidențiat absența semnelor de recidivă locală şi absența leziunilor secundare, deci răspuns complet al bolii la tratament.

\section{DISCUTุII}

Hepatoblastomul este o tumoră foarte rară (1-2\% din totalul neoplaziilor la copil), dar reprezintă $80 \%$ din totalul tumorilor hepatice maligne la copil $(3,4)$. Boala apare mai frecvent la băieți de rasă albă cu vârsta mai mică de 3 ani. (5)

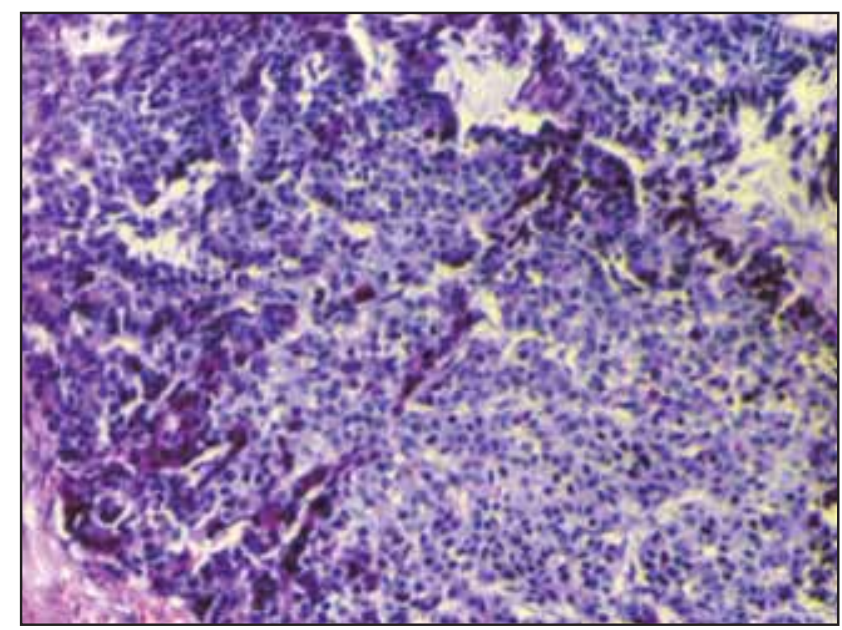

b

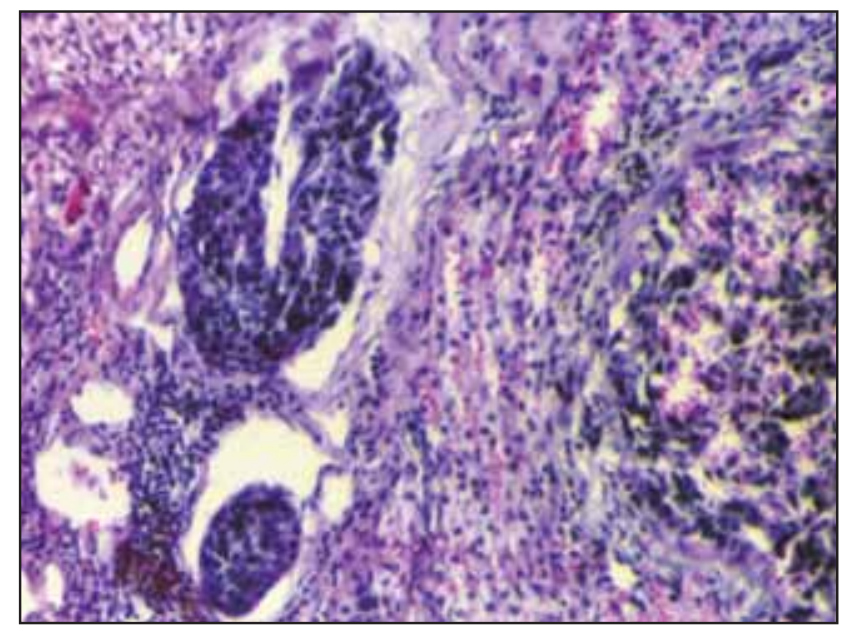

$\mathrm{d}$

FIGURA 2 - a. Noduli tumorali; b. Invazie vasculară; c. Mitoze, HE x 400; d. Hepatoblastom embrionar şi fetal, HE x 10 
Etiopatogeneza hepatoblastomului nu este complet elucidată. Tumora a fost asociată în aproximativ $15 \%$ din cazuri cu unele sindroame genetice ereditare. (6-9) Multipli factori de mediu au fost incriminați ca factori cauzali în hepatoblastom, însă a fost dovedit doar că statusul de fumător al părinţilor şi greutatea mică la naştere a copilului cresc riscul de apariție al acestei neoplazii. (10-17)

Simptomele şi semnele cele mai comune sunt: masă abdominală palpabilă simptomatică sau asimptomatică $(68 \%$ cazuri), anorexie $(23 \%)$, durere abdominală (19\%), vărsături (11\%) sau pubertate precoce. Cel mai frecvent situs de metastazare este plămânul, dar au fost descrise în literatură şi leziuni secundare la nivelul cordului, sistemului nervos central sau la nivelul arterei pulmonare. $(2,18-21)$

Investigațiiile biologice pot decela valori crescute ale AFP (de obicei $>50.000 \mathrm{ng} / \mathrm{ml}$, iar valorile $>100.000 \mathrm{ng} / \mathrm{ml}$ sugerează boală avansată sau metastaze). (22,23). În cazul nostru s-a observat o reducere a nivelului AFP de la valori $>30.000 \mathrm{UI} / 1$ înregistrate iniţial şi postoperator precoce, la normalizarea valorilor în luna iulie.

Metodele de diagnostic se bazează în principal pe imagistică. Inițial se efectuează ultrasonografie abdominală. CT-ul şi RMN-ul joacă un rol esențial în stadializarea neoplasmului.

Diagnosticul diferențial include toate tipurile de mase hepatice: benigne (hemangiom, hemangioendoteliom, hiperplazie focală nodulară, chisturi hepatice posttraumatice, congenitale sau echinococale) sau maligne (sarcom nediferențiat, rabdomiosarcom, mezenchim malign, hepatocarcinom). (24)
Tratamentul hepatoblastomului este standardizat. Grupul SIOPEL preferă chimioterapia preoperatorie şi câteva cicluri de chimioterapie postoperatorie, în timp ce Intergrupul American foloseşte chirurgia per primam, apoi chimioterapia postoperatorie. Chimioterapia se bazează pe un protocol cu doze mari de cisplatin în ambele grupuri.

Hepatoblastomul cu metastaze este clasificat ca fiind $\mathrm{cu}$ risc înalt. Rezultatele terapeutice pentru aceste tumori sunt considerabil inferioare (supraviețuire generală la 3 ani de $50 \%$ ) comparativ cu hepatoblastoamele cu risc standard (limitate la ficat sau la cele 3 sectoare hepatice) care au o supraviețuire generală de $90 \%$ la 3 ani. Din acest motiv tratamentul hepatoblastomului cu risc înalt reprezintă o provocare pentru medicul oncolog pediatru. Protocolul de chimioterapie SIOPEL-4 se foloseşte pentru neoplasmele aflate în acest stadiu. În cadrul lui se utilizează cisplatin (C) şi doxorubicină (D) pentru blocurile A1, A2, A3 şi carboplatin (CA) şi doxorubicină (D) pentru blocurile B şi C. (Fig. 3).

În cazul prezentat $\mathrm{s}-\mathrm{a}$ decis inițierea chimioterapiei postoperatorii, conform protocolului SIOPEL-4 modificat. Astfel, toate blocurile de chimiote-rapie care trebuiau administrate preoperator au fost administrate postoperator în aceleaşi doze. (Fig. 4).

$\mathrm{Cu}$ acest protocol de tratament, pacientul nostru a avut un răspuns tumoral complet. Din cunoştinţele noastre este primul caz descris în literatură care are această particularitate.

Transplantul hepatic reprezintă o opțiune de luat în considerare pentru pacienții cu tumoră nerezecabilă şi/sau metastaze pulmonare. Este de preferat

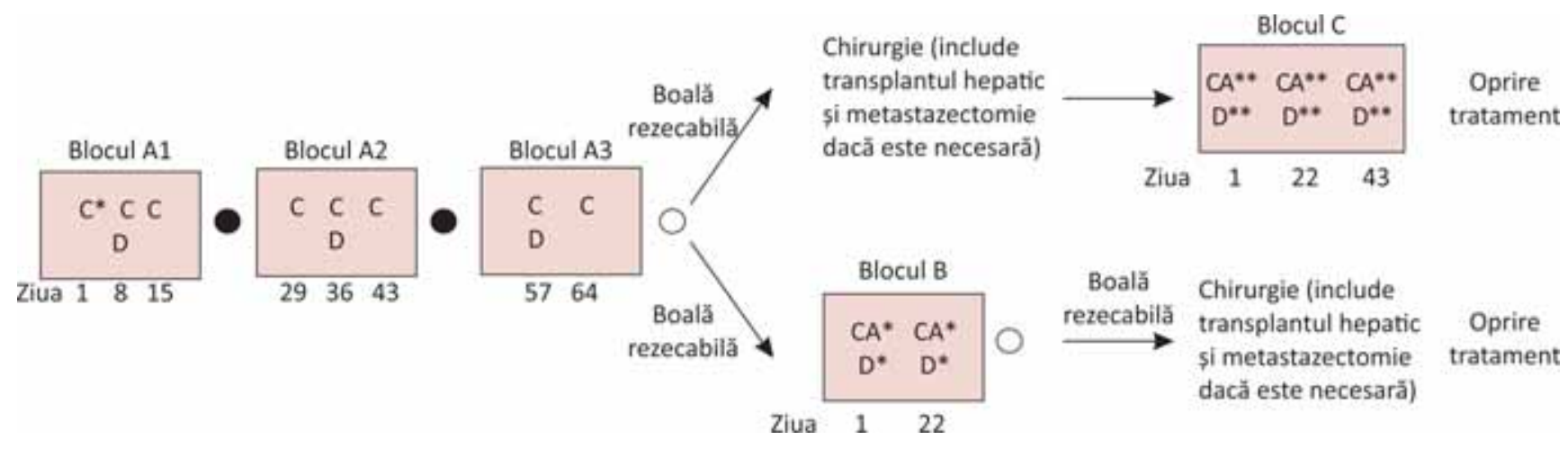

FIGURA 3. Schemă protocol SIOPEL-4 utilizat în tratamentul hepatoblastomului cu risc înalt

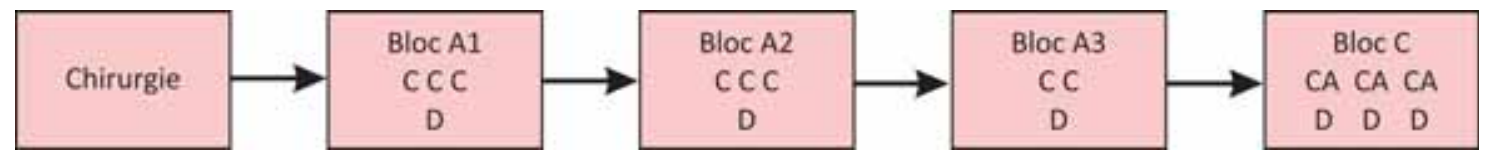

FIGURA 4. Protocol SIOPEL-4 modificat folosit în cazul pacientului nostru 
să se folosească transplantul hepatic de primă intenție, întrucât rezultatele sunt mult superioare în ceea ce priveşte supraviețuirea. Totuşi, pentru ca transplantul hepatic să se poată efectua, este necesar ca toate metastazele pulmonare să fie rezecate complet sau să răspundă complet la chimioterapie. Absența acestora trebuie să fie confirmată prin CT sau RMN. Încercările de hepatectomie parțială care au risc crescut de rezecție incompletă trebuie evitate. (25)

\section{CONCLUZII}

Hepatoblastomul cu metastaze pulmonare are un prognostic nefavorabil. În prezent se încearcă găsirea unor noi opțiuni terapeutice care să îmbunătățească supraviețuirea şi calitatea vieții pentru aceşti bolnavi. În cazul prezentat s-a obținut răspuns complet tumoral la un copil cu hepatoblastom cu metastaze pulmonare. Aşadar, schimbarea protocoalelor de chimioterapie ar putea reprezenta una dintre soluții pentru îmbunătătirea prognosticului acestor pacienți. 